\title{
PSEUDO TUMOUR OF THE ORBIT AND POLYARTERITIS NODOSA
}

\author{
BY \\ E. W. WALTON \\ From the Department of Pathology, King's College, Durham University, in the Royal Victoria Infirmary, \\ Newcastle upon Tyne
}

(RECEIVED FOR PUBLICATION DECEMBER 14, 1958)

Pseudo tumour of the orbit, or chronic granuloma as it is frequently called, is a fairly common clinical condition. Though most cases are of unknown aetiology, a few prove to be manifestations of systemic disease. The purpose of this paper is to report a case where the clinical diagnosis of pseudo tumour of the orbit was made and polyarteritis nodosa, suspected during life, was confirmed at necropsy.

\section{Case Report}

W. O. Y., a bus conductor, aged 53 years, was first seen on August 29, 1955. For two months he had had shooting pains in the left temple with frequent headache. A month later the vision of the left eye deteriorated and he was told the eye bulged forwards. He then had two brisk epistaxes. On examination the right eye was normal; the left showed $5 \mathrm{~mm}$. proptosis, limitation of all movements, and absence of the direct light reflex, though the consensual reflex was present. A dense central scotoma was demonstrated on the left side, yet the fundus appeared normal. The pulse was 76 per minute, blood pressure $150 / 90 \mathrm{~mm}$. Hg. Radiological examination showed opacity of the left posterior ethmoidal region with a suggestion of bone destruction. A blood count was normal apart from slight anaemia (haemoglobin $12.7 \mathrm{~g}$. per $100 \mathrm{ml}$.), and the plasma proteins showed reversal of the $A / G$ ratio (total $6.6 \mathrm{~g}$. per $100 \mathrm{ml}$., albumin $2.8 \mathrm{~g}$., globulin $3.8 \mathrm{~g}$.). Blood Wassermann and Kahn reactions were negative. The urine contained a trace of albumin but no abnormal cells and the blood urea was $66 \mathrm{mg}$. per $100 \mathrm{ml}$. Exploration of the ethmoidal and sphenoidal air cells revealed thick mucus only: a biopsy of the thickened mucosa showed a granulomatous lesion of chronic, non-specific type with marked endarteritis but no micro-organisms.

Despite treatment with penicillin, he did not improve and within some five weeks was blind in the left eye. The pupil was fixed, the veins were engorged, and optic atrophy had developed. Orbitonometry showed a progressive increase in the proptosis and in the consistency of the orbital contents. Exenteration of the orbit was performed on October 13 (sixth week). A hard pale mass was found in the posterior ethmoidal air cells, penetrating the superior and inferior orbital fissures to surround the optic nerve. The histological report on the biopsy was:

"The specimen shows a granulomatous lesion described as pseudo tumour of the orbit. As similar material was removed from the ethmoid, it is likely that the lesion originates there. Lesions of the above type have been described in association with periarteritis nodosa. Is there evidence of systemic disease in this patient?" (Dr. R. O. K. Schade).

After the operation the headaches ceased but recurred two weeks later on the right side. Blurring of vision appeared and a dense central scotoma was demonstrated, similar to that which previously developed in the left eye. A course of $x$-ray therapy was given to the posterior orbit in an endeavour to arrest the disease, but the patient's general condition began to worsen; he developed a swinging temperature and became very apathetic. On November 28 signs of peritonitis appeared and at laparotomy a gangrenous, perforated appendix was removed. His condition rapidly deteriorated and he died the following day. There was no terminal rise in blood pressure.

\section{Necropsy}

The body was wasted. The left orbit was lined by an apparently healthy graft. Apart from the recent surgical incision in the abdomen there was nothing else of note externally.

Skull.-The dura in the anterior cranial fossae and over the vertex was diffusely thickened and a purulent pachymeningitis was present, localized to these areas. The right orbit, the frontal, maxillary, and anterior and middle ethmoidal sinuses appeared normal. The bone over both the sphenoidal and the left posterior ethmoidal sinuses was elevated and thinned; these air cells contained 
a smooth, fleshy mass of yellowish material, homogeneous and adherent to bone. Pus was present in the nasal cavity. The brain, pituitary, and middle ears were normal. The mucosa of the nasopharynx and soft palate was congested; otherwise the mouth, tonsils, fauces, and pharynx were healthy.

Chest.-The lungs were heavy and on section showed areas of early bronchopneumonia: the bronchial tree and main pulmonary vessels were normal. The heart was of normal size. The coronary arteries, especially the descending branch of the left vessel, were tortuous and showed many nodular thickenings which on section were small aneurysms, filled with recent thrombus. The aorta and its main branches were normal apart from atheroma.

Abdomen.-A recent fibrinous peritonitis was present. Numerous mucosal erosions were present in the bowel, especially in the ileum and rectosigmoid. The liver was of normal size and the parenchyma was mottled and congested: numerous ante-mortem thrombi were present in major branches of the portal vein and in nodosities of the hepatic artery (Fig. 1). The spleen weighed $300 \mathrm{~g}$. and was extensively infarcted (Fig. 2). The kidneys together weighed $520 \mathrm{~g}$. Multiple recent infarcts were present in each and the cortices were extensively swollen and blurred. Many of the main branches of each renal artery contained thrombus (Fig. 3). Infarcts were present in each testis (Fig. 4).

The gastroduodenal, left spermatic, and left gastric arteries and major branches of the splenic, hepatic, renal, and superior mesenteric arteries were grossly nodular, the aneurysms all containing ante-mortem thrombus. The other main vessels were healthy. All other organs and tissues were normal. Bacteriological examination of material from the paranasal sinuses was negative.

\section{Histology}

Review of the biopsies from the left orbit and ethmoidal sinuses shows in each a chronic granuloma of non-specific type. In the orbit the granuloma tightly ensheaths the optic nerve and has replaced much of the orbital fat. The dense cellular infiltrate consists largely of macrophages, plasma cells, lymphocytes, and neutrophil polymorphs: eosinophil polymorphs are quite frequent, but there is no epithelioid cell reaction and the infrequent giant cells are of foreign body type. The infiltrate, perivascular in places (Fig. 5), has in most areas fused to form a solid mass. The lymphocytes are in places arranged into pseudo follicles without germ centres. At the periphery, the lesion invades the orbital muscles. Many vessels, both arterioles and venules, show perivascular infiltration but are otherwise normal.

The ethmoidal mucosa is greatly thickened by fibrous tissue and patchily infiltrated by cells of similar type but fewer in number than in the orbital granuloma. There are no giant cells and no focal granulomata. The arteries show fibrosis of all layers with reduplication of elastica and narrowing of the lumen. No defects of elastica are present, and the lesions, though reminiscent, are not diagnostic of polyarteritis nodosa. Similar changes are seen in the necropsy specimens from the sphenoidal and left ethmoidal air cells. No micro-organisms are seen in sections from each granuloma stained by the Ziehl-Neelsen, Gram, and P.A.S. methods. Areas of myelin degeneration are present in the right optic and oculomotor nerves; there is infarction in the ocular muscle. but no granuloma is present on this side.

The necropsy material shows vascular lesions (Figs. 6-11) in many organs and tissues (Table I).

TABLE I

SITES OF LESIONS

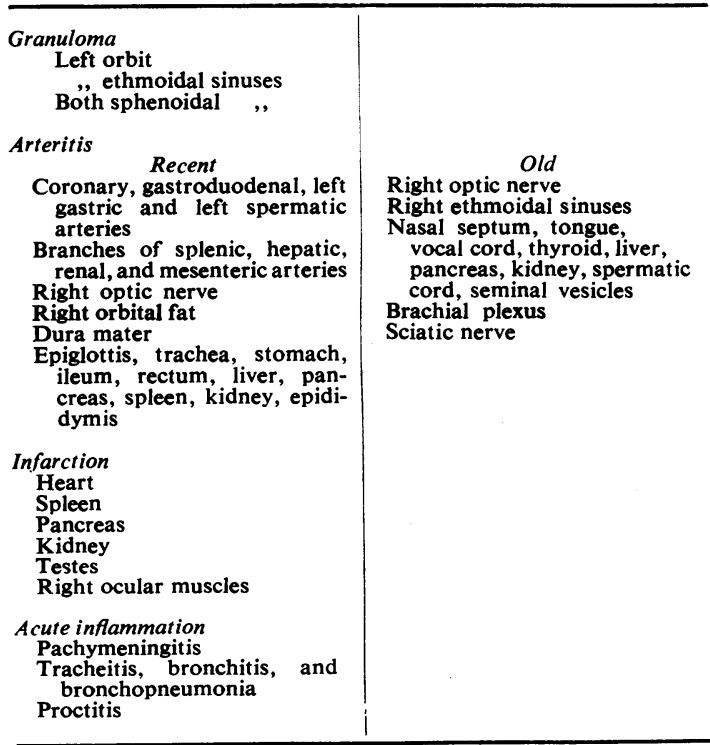

Small and medium-sized arteries are principally involved though occasional affected arterioles and even capillaries are seen in the spleen and kidneys. Veins are not affected though thrombi are present in small veins in the liver, kidney, and lacrimal glands. The lesions are focal and often segmental 
FIG. 1-Liver slice showing numerous ante-mortem thrombi in branches of portal vein and hepatic artery. Irregular fixation has increased the mottling of the tissue.

Fig. 2.-Cut surface of spleen to show the extensive infarction.

FIG. 3.-Slice of left kidney showing multiple recent infarcts. Ante-mortem thrombus is present in many branches of the renal artery.

Fig. 4.-Hemi section of right testis to show the ext ensive infarction.

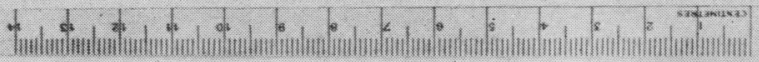

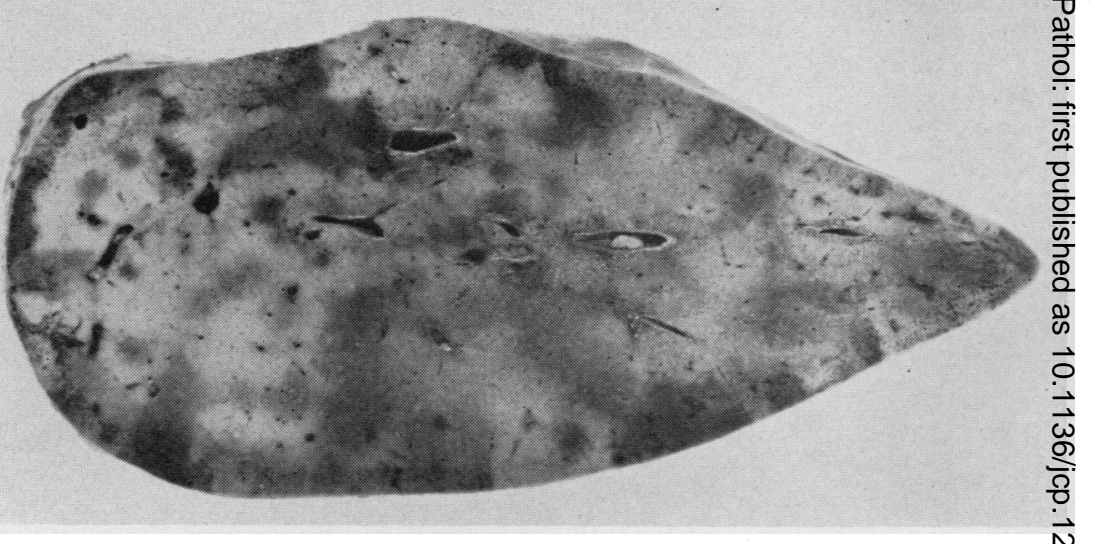

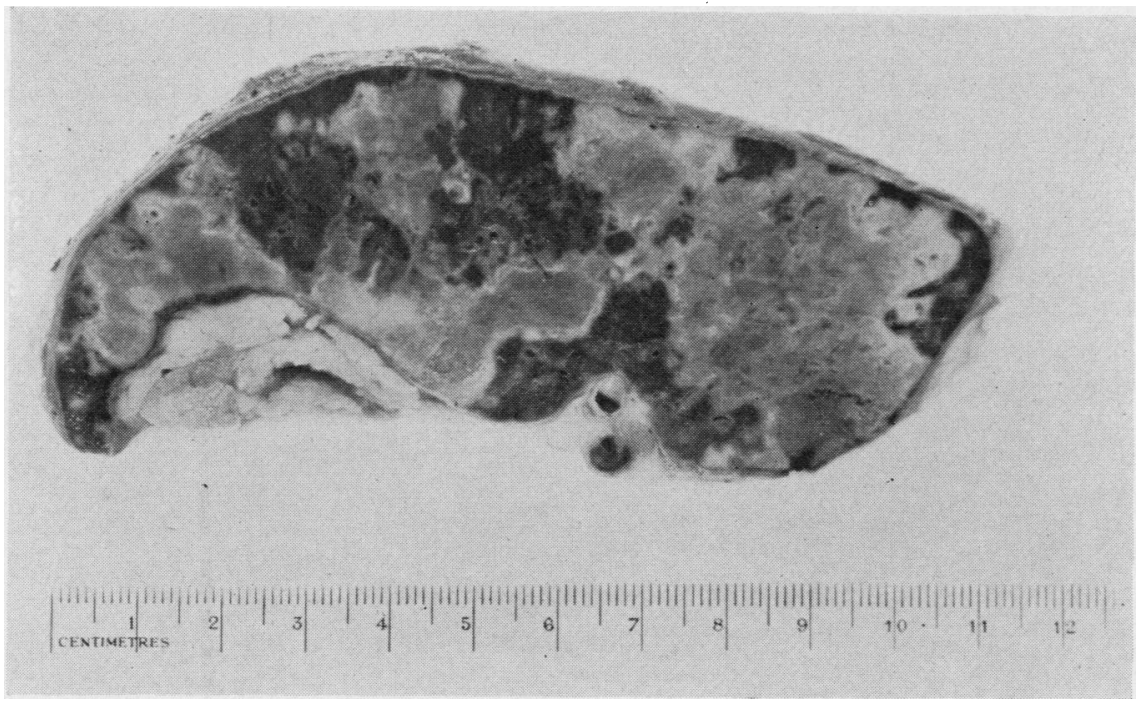

Fio. in

$\stackrel{\overrightarrow{0}}{0}$

FIG. 2
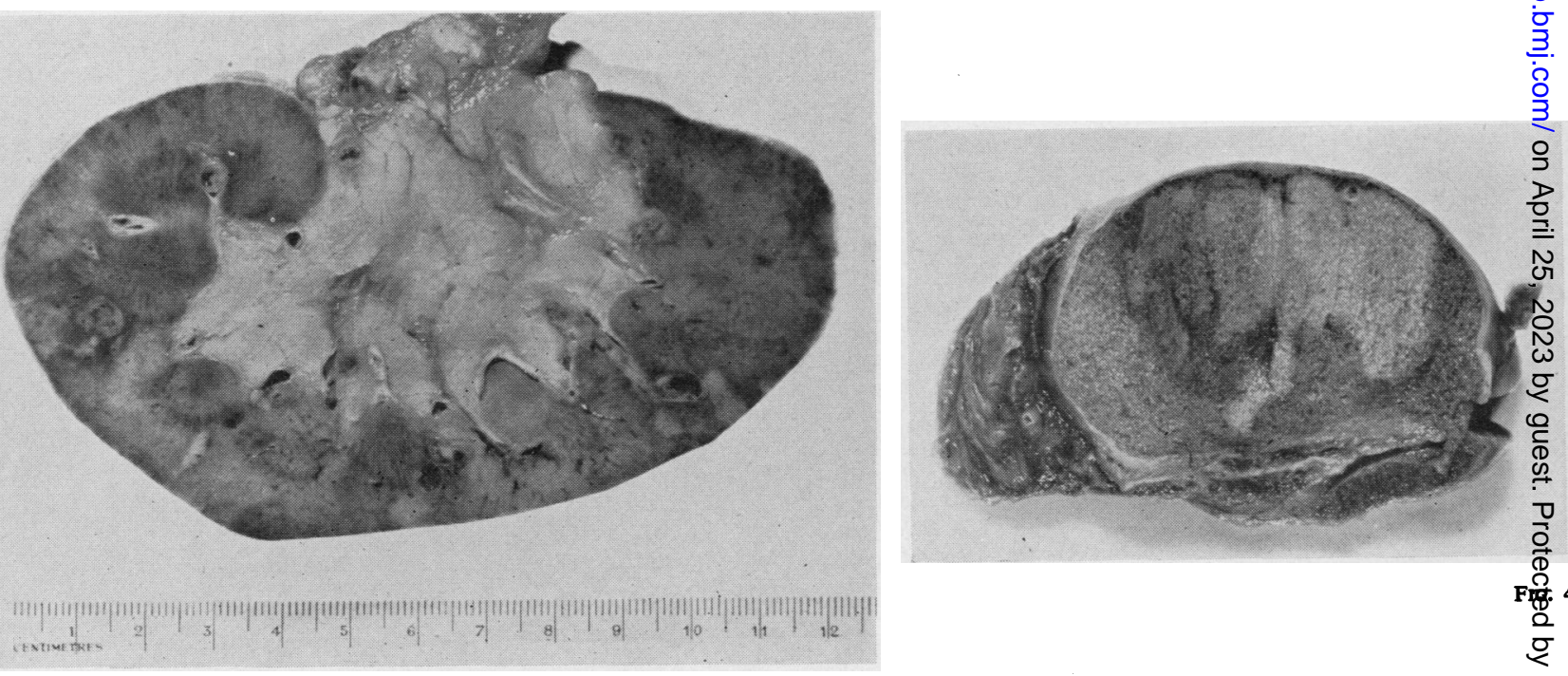

FIG. 3 


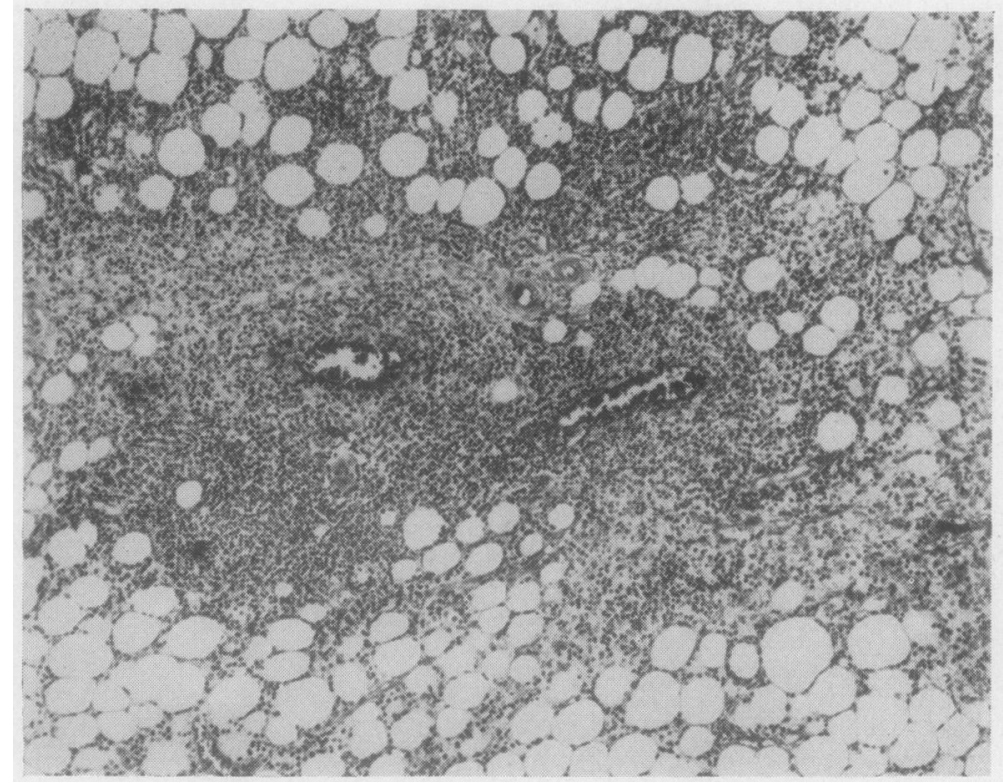

Fio. 5

FIG. 5.-Low-power view of part of the orbital granuloma showing that in parts the infiltrate is perivascular. Haematoxylin and eosin, $\times 70$.

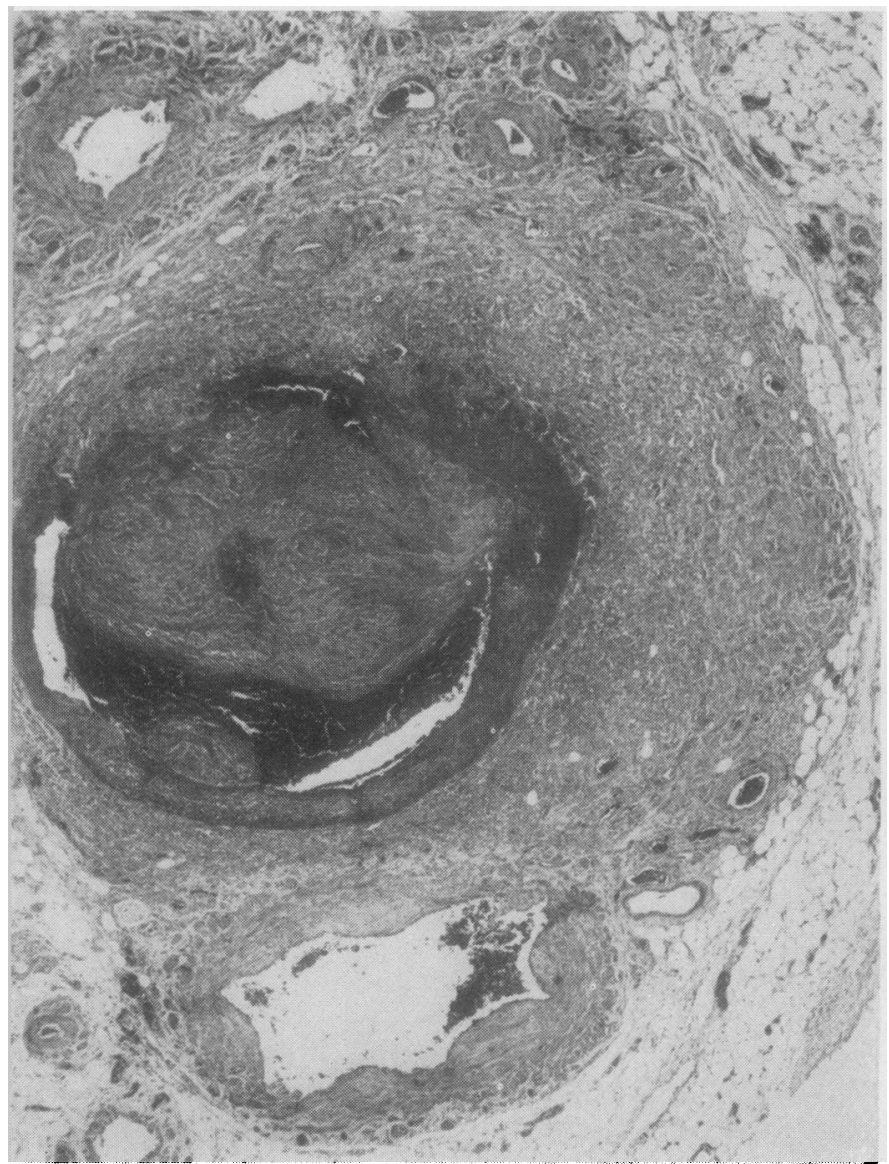

Fig. 6.-Section of a coronary artery with acute necrosis of a segment of the wall and almost complete occlusion of the lumen by thrombus. Serial sections of the lesion confirm that the vessel is slightly dilated at this point. Haematoxylin and eosin, $\times 27$.

FIG. 7.-This section of pancreas shows an acute lesion at a point of arteriolar branching. One limb contains thrombus. Haematoxylin and eosin, $\times 112$.

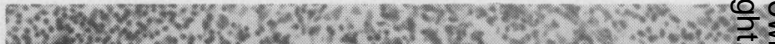

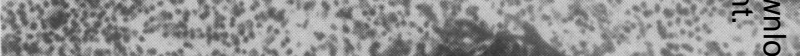
30.345,

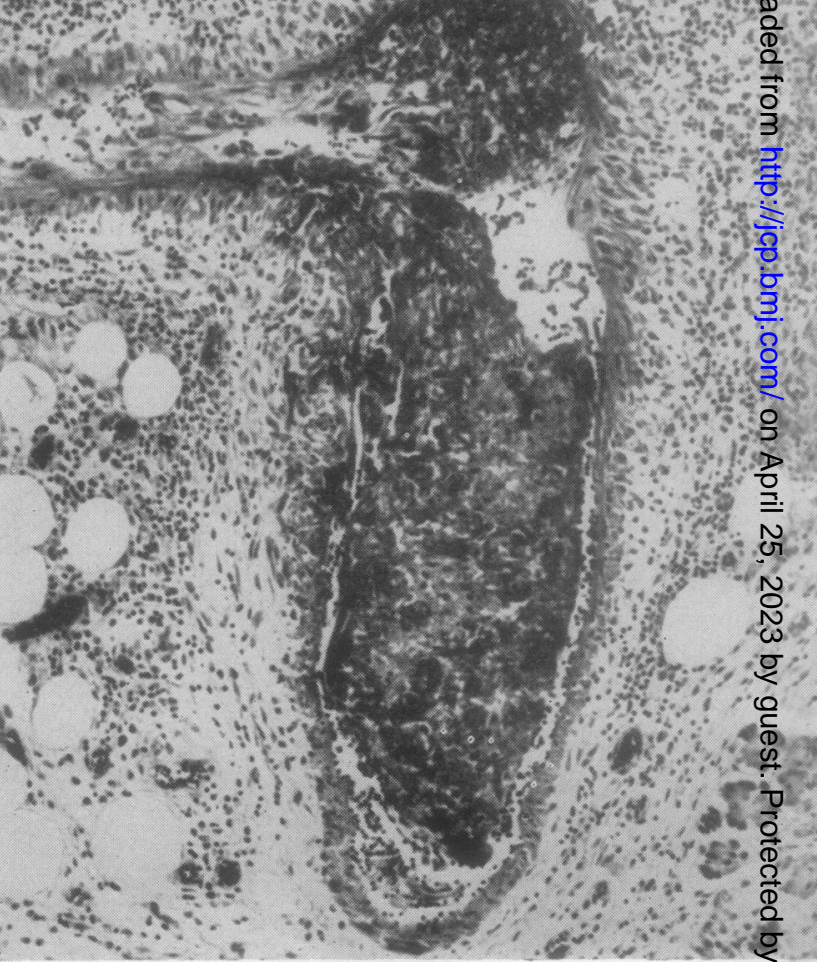

FIG. 7 


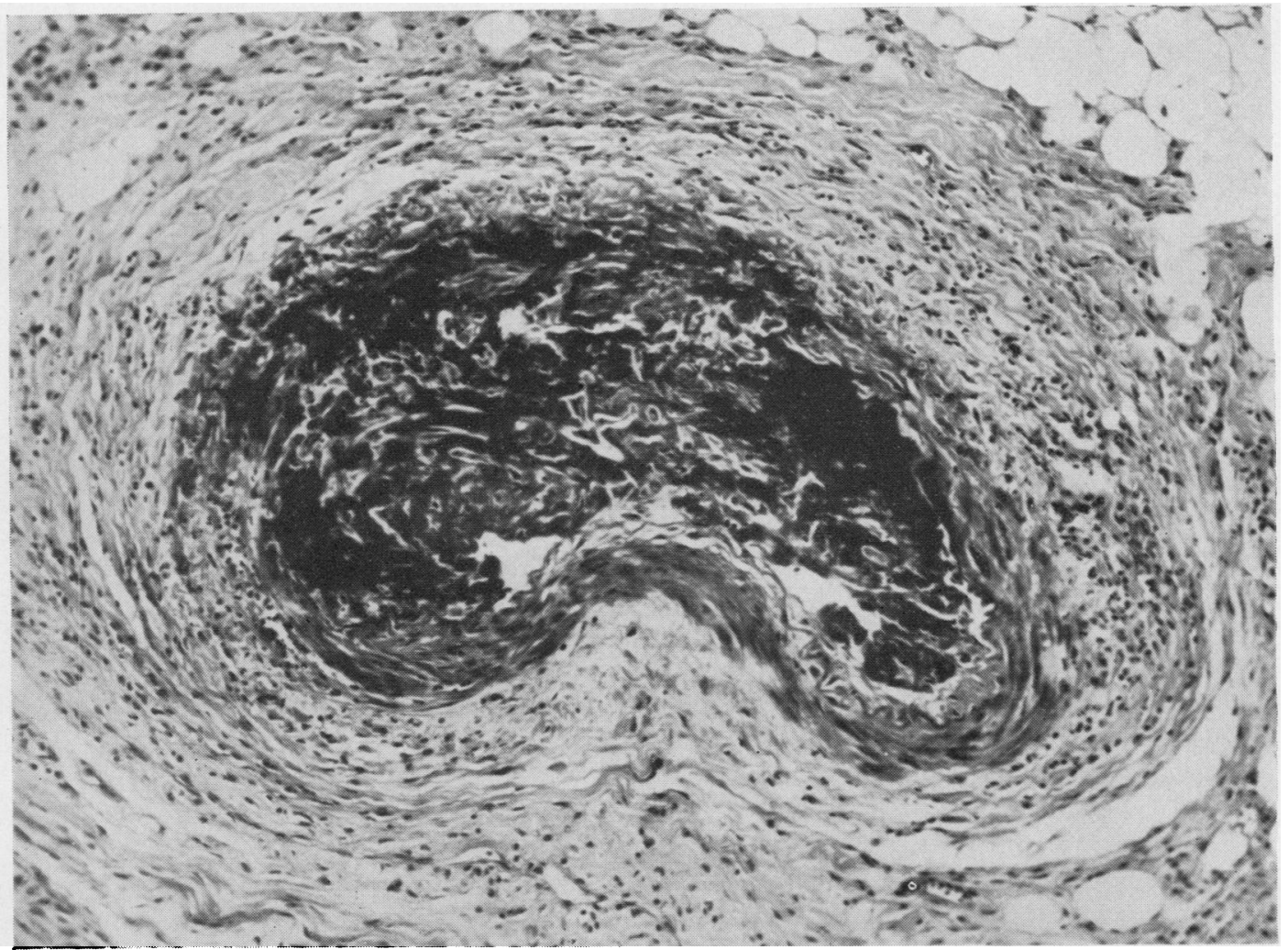

FIG. 8.-Acute necrosis and thrombosis of an arteriole in the adipose tissue of the right orbit. Haematoxylin and eosin, $\times 144$.

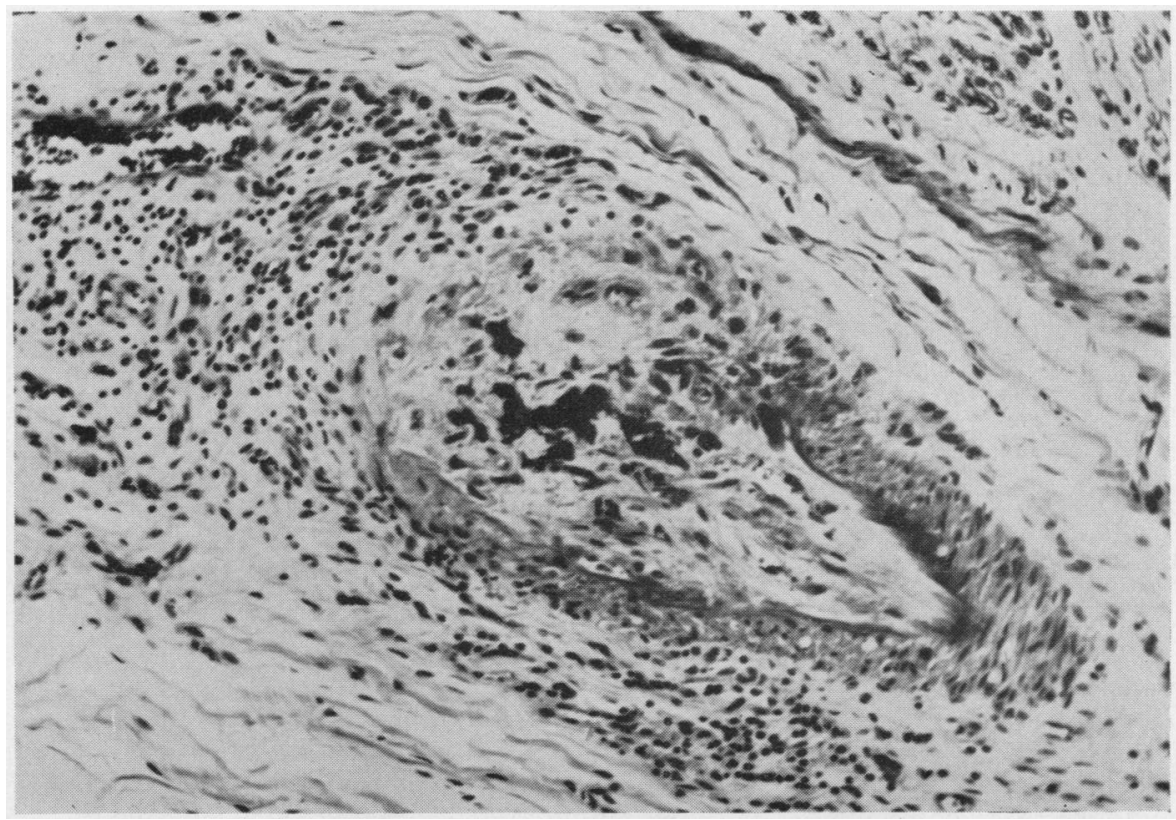

Fig. 9.-Healing lesion in an arteriole from the right superior oblique muscle. Part of the vessel wall has been replaced by granulation tissue and the lumen is occluded by partly organized thrombus. Haematoxylin and eosin, $\times 160$. 


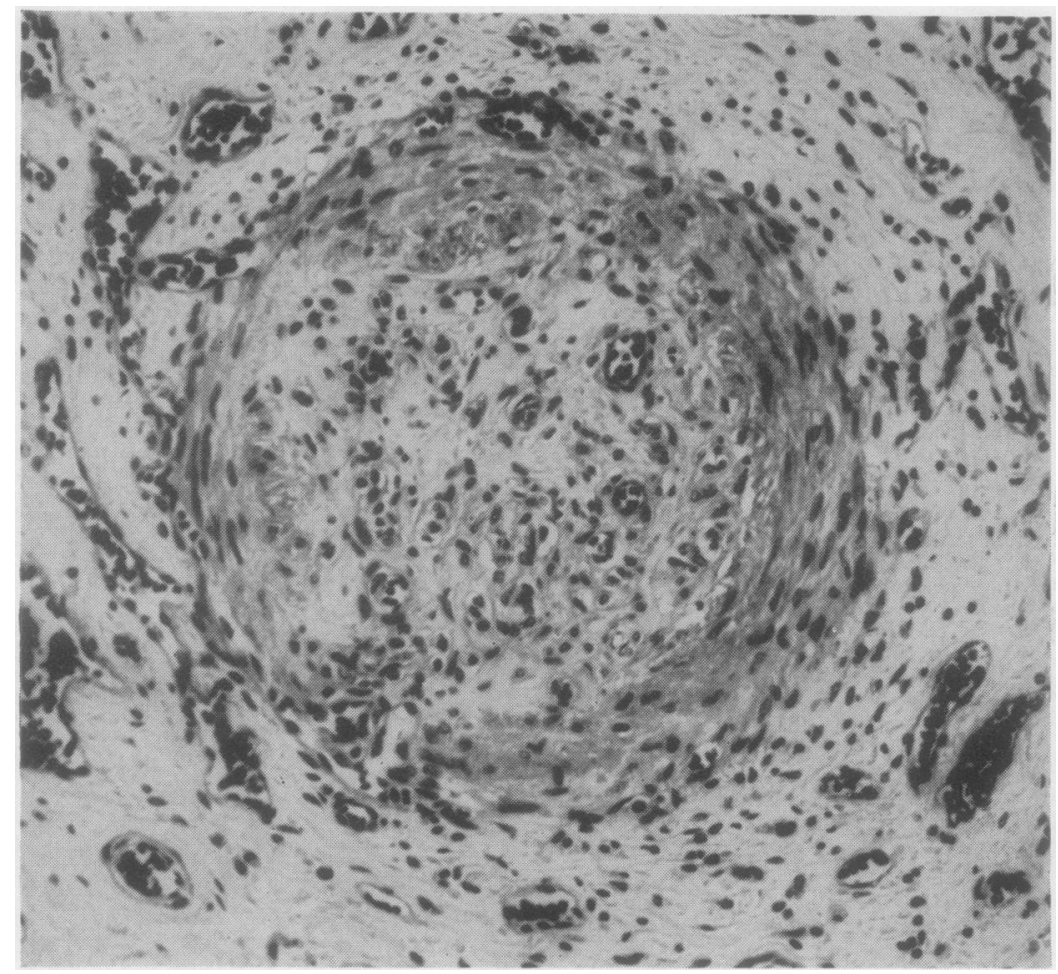

FIG. 10.-This section of a nerve trunk from the brachial plexus shows a healing lesion in an arteriole. The wall of the vessel is patchily scarred and the lumen is filled with fibrous tissue containing numerous capillaries. Haematoxylin and eosin, $\times 185$.

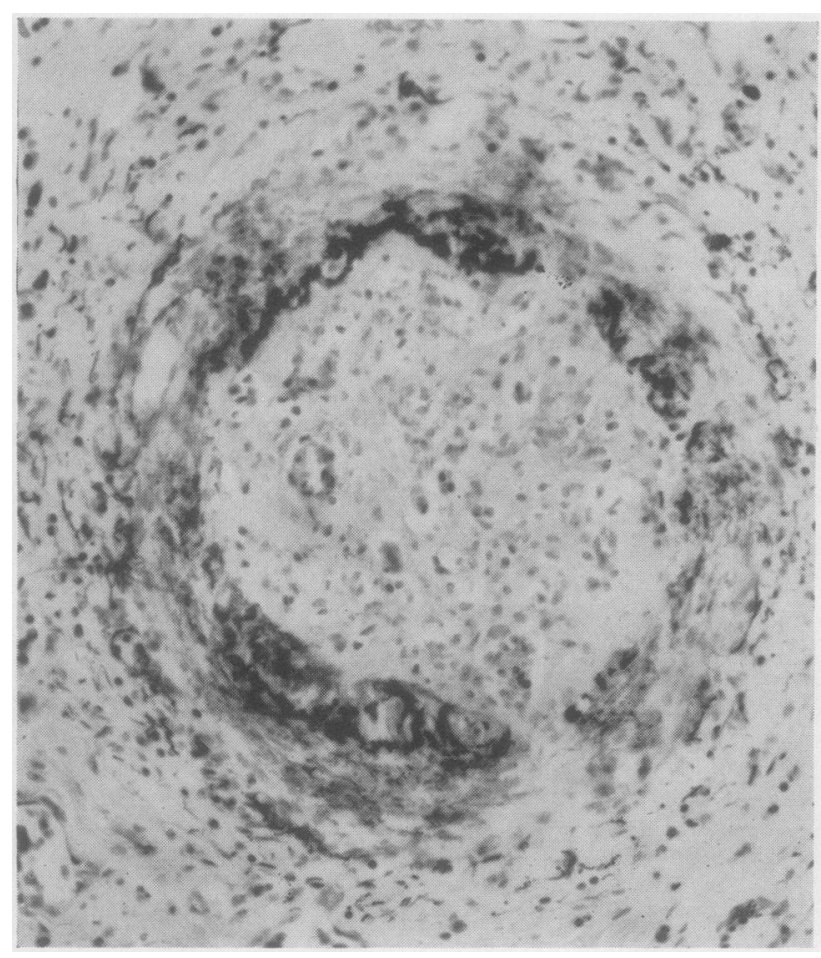

FIG. 11.-Serial section to Fig. 10, to show fragmentation of the elastica. Weigert's elastica and scarba red, $\times 150$. and appear to have a predilection for sites of branching (Fig. 7). In the acute phase (Figs. 6-8) the affected vessels show material, giving the staining reactions of fibrin, seeping into, and sometimes beyond, their walls. Oedema, especially of the intima, infiltration of all layers with neutrophil polymorphs and macrophages, and thrombosis, are other features. 'In places, the wall of the larger affected vessels has dilated to give a small aneurysm (Fig. 6). Healing lesions (Figs. 9-11) show organization of and formation of new vessels in the luminal thrombus whilst the hallmark of the healed lesion is segmental absence of the elastica (Fig. 11). These lesions are typical of polyarteritis nodosa. Associated with the vascular disease are infarcts of heart, spleen, pancreas, kidneys, testes, and the right ocular muscles.

No vascular or granulomatous lesions are present in the trachea, lung, or bronchi, and no giant-cell granulomata are seen in any of the visceral sections. A few glomeruli show fibrinoid change of capillaries, but most are normal. The aorta, subclavian, iliac, and carotid arteries are normal, apart from atheroma. Non-specific inflammatory lesions include an acute pachymeningitis, acute tracheitis, bronchopneumonia, acute proctitis, and acute on chronic rhinitis and antral sinusitis. 
Other organs and tissues examined, including brain, skin, voluntary muscle, tonsil, salivary gland, lymph nodes, and bone marrow, appear normal.

\section{Discussion}

This case presents the coexistence of two syndromes, pseudo tumour of the orbit and polyarteritis nodosa, both incompletely understood and both uncommon. The association is so rare that I have found only one detailed report, that by Hope-Robertson (1956). Two further cases are briefly discussed by Reese $(1951,1956)$ whilst Case 1 of Howells (1955) and that of Bellomio (1953) are probably further examples. It is not mentioned by Duke-Elder (1952) in his section on chronic orbital inflammation nor by Jackson (1958) in his recent review of pseudo tumour.

The term "pseudo tumour of the orbit" has a clinical rather than a pathological connotation and " may be taken as embracing a considerable group of cases which are difficult to differentiate clinically from an orbital tumour but which on pathological investigation or by their resolution under treatment are shown to be granulomata of chronic inflammatory type" (Duke-Elder, 1952). Reese (1951) has distinguished five varieties, with the following histological features: (1) Prominent lymph follicles; (2) focal and perivascular infiltrations of lymphocytes and involvement of muscle; (3) chronic inflammation widely spread throughout the tissue and varying degrees of fibrosis and polymorph infiltration; (4) early fibrosis with little inflammation; (5) inflammation in a pre-existing angioma.

The lesion in the present case, in which there is both involvement of muscle and the development of occasional lymph follicles, does not fall readily into any of these categories; it most closely resembles type 3 .

Occasionally, orbital granulomata are associated with systemic disease, and Reese (1951) has noted the association with sarcoidosis, leukaemia, syphilis, tuberculosis, and HandSchüller-Christian disease. Excluding these cases, and those of type 5 in which an angioma is probably the original lesion, the aetiology of pseudo tumour is unknown.

Though there is widespread agreement that polyarteritis nodosa is not a homogeneous entity, no commonly agreed classification exists. Perhaps the best is that of Rose and Spencer (1957), who differentiated between cases with and without pulmonary involvement. In the former there is usually a prior respiratory illness such as asthma or pneumonia; eosinophilia is common; necrotizing parenchymal and vascular lesions are found in the lungs; and the affected vessels, usually small, often show giant-cell granulomata. This group appears to include several of Zeek's (1952) categories, especially "allergic granulomatous angiitis," and a history of hyperergic disease is common to most. In the second group, granulomatous lesions are rare and the pulmonary vessels are not involved while there is no association with respiratory illness. This group is apparently identical with the "classical" polyarteritis nodosa of older authors and the "true periarteritis nodosa" of Zeek. Though hypertension has often been postulated as the causal factor in this type, Rose and Spencer (1957) have shown that it is confined to those cases in which there are healed vascular lesions in the kidneys ; it would appear therefore to be a sequel rather than a cause of the disease. In the present case, the changes were clearly of this second category; there were few healing lesions in the kidneys and hypertension did not develop.

The interest in this case lies in the possibility that the coexistence of the two lesions, pseudo tumour of the orbit and polyarteritis nodosa, may lead us to a clearer understanding of the aetiology of each. Three possibilities exist: first, that the polyarteritis was secondary, both in time and in causation, to the orbital granuloma; secondly, that the granuloma was a consequence of the polyarteritis; and, thirdly, that the presence of the two lesions was coincidental. Before considering these propositions, we may note that there are two sets of circumstances in which granulomata and polyarteritis nodosa are constantly associated. In one, "allergic granulomatous angiitis" (Churg and Strauss, 1951), asthma is a common factor and allergy the probable cause. In the other, to which the eponym "Wegener's granulomatosis" has been applied, there is granulomatous ulceration of the upper air passages. I have shown elsewhere (Walton, 1958) that the polyarteritis in this group is secondary to the granuloma and is probably the result of a hypersensitivity reaction.

To return to the three possibilities, asthma was not a feature of the present case, but it is tempting to suggest that, by analogy with Wegener's granulomatosis, the polyarteritis in it was likewise secondary to a granuloma, in this case arising in the orbit and sinuses. There are, however, significant differences between Wegener's granulomatosis and this case. In the former condition the granulomata have giant cells and central necrosis and are widely distributed. The vascular lesions are akin to those in Rose and 
Spencer's (1957) first group, small vessels in the lung being especially involved. In the case under discussion, no giant cells were found in the lesions, the granulomata were present only in the orbit and paranasal sinuses, the lungs were not affected, and the vascular lesions, involving mainly vessels of medium size, clearly come into Rose and Spencer's second category. Furthermore, no clinical evidence of hypersensitivity was noted. There is thus no convincing evidence that the vascular lesions were caused by the orbital granuloma.

More likely is the second possibility that the orbital and sinusoidal lesions were a result of the polyarteritis, being the sequel of confluence of numerous perivascular infiltrates. In the case of polyarteritis nodosa with chronic orbital myositis described by Bellomio (1953), inflammatory lesions of the orbital muscles were thought by the author to be the direct result of polyarteritis. In Hope-Robertson's (1956) case an interval of two and a half years elapsed between the diagnosis of pseudo tumour of the orbit and the demonstration at necropsy of polyarteritic lesions. In the present case, re-examination of serial sections from the orbital and sinusoidal biopsies showed no vascular lesions of the kind at necropsy. This proposition is therefore no more than surmise and very possibly the coexistence of the two lesions is mere coincidence. Nevertheless, it seems justifiable to suggest, on the basis of this case, that in cases of orbital granuloma, especially in the presence of symptoms and signs of widespread disease, a vasculitis should be considered as a possible aetiological factor.

\section{Summary}

A case is reported in which the presenting clinical picture was that of pseudo tumour of the orbit. At necropsy, polyarteritis nodosa, suspected during life because of the perivascular nature of the orbital granuloma, was confirmed. The bearing this rare association has on the aetiology of pseudo tumour, the relationship with Wegener's granulomatosis, and the classification and aetiology of necrotizing arteritis are briefly discussed.

I am indebted to $\mathrm{Mr}$. $\mathrm{H}$. Vernon Ingram for permission to publish this case, to Mr. A. E. Young and Mr. J. W. Corkhill for the illustrations, and to Professor J. B. Duguid, Professor A. C. Lendrum, Dr. R. O. K. Schade, Dr. I. Rannie, and Dr. W. W. Park for advice and encouragement.

\section{REFERENCES}

Bellomio, S. (1953). Riv. ital. Tracoma, 5, 103.

Churg, J., and Strauss, L. (1951). Amer. J. Path., 27, 277.

Duke-Elder, S. (1952). Text-book of Ophthalmology, Vol. 5, p. 5448. Henry Kimpton, London.

Hope-Robertson, W. J. (1956) Trans ophthal Soc. N.Z. 8, 56. Howells, G. H. (1955). J. Laryng., 69, 309.

Jackson, H. (1958). Brit. J. Ophthal., 42, 212.

Reese, A. B. (1951). Tumors of the Eye, p. 522. Paul B. Hoeber, New York.

(1956). Atlas of Tumor Pathology, Section X, Fascicle 38: Tumors of the Eye and Adnexa, p. 204. Armed Forces Institute of Pathology, Washington, D.C.

Rose, G. A., and Spencer, H. (1957). Quart. J. Med. n.s., $26,43$.

Walton, E. W. (1958). Brit. n'ed. J., 2, 265.

Zeek, P. M. (1952). Amer. J. c'in. Path., 22, 777. 